\title{
Influence of Hydrodynamic Conditions on Quantitative Cellular Assays in Microfluidic Systems
}

\author{
Huabing Yin, ${ }^{\dagger}$ Xunli Zhang, ${ }^{\ddagger}$ Nicola Pattrick, $\$$ Norbert Klauke, ${ }^{\dagger}$ Hayley C. Cordingley, $§$ \\ Stephen J. Haswell,‡ and Jonathan M. Cooper*,†
}

Department of Electronics and Electrical Engineering, University of Glasgow, Glasgow, G12 8LT, U.K., Department of Chemistry, University of Hull, Hull, HU6 7RX, U.K., and Technology Development, GlaxoSmithKline Pharmaceuticals, Harlow, CM19 5AW, U.K.

This study demonstrates the importance of the hydrodynamic environment in microfluidic systems in quantitative cellular assays using live cells. Commonly applied flow conditions used in microfluidics were evaluated using the quantitative intracellular $\mathrm{Ca}^{2+}$ analysis of Chinese hamster ovary (CHO) cells as a model system. Above certain thresholds of shear stress, hydrodynamically induced intracellular $\mathrm{Ca}^{2+}$ fluxes were observed which mimic the responses induced by chemical stimuli, such as the agonist uridine $5^{\prime}$-triphosphate tris salt (UTP). This effect is of significance given the increasing application of microfluidic devices in high-throughput cellular analysis for biophysical applications and pharmacological screening.

Cell-based assays have been performed in a variety of sectors in the life sciences, particularly those associated with biotechnology and the pharmaceutical industries. Many cellular assays use intact cells to obtain functional information on cell signaling pathways as well as kinetic data related to drug absorption, metabolism, and toxicity. In recent years there have been rapid developments in cell-based assays in microfluidic systems, particularly in the area of lab-on-a-chip, enabling the efficient analysis of complex biological phenomenon within microscale systems. ${ }^{1}$ Clearly, the generation of quantitatively reliable information onchip, which is a true reflection of the cell's response to a drug or an analyte, remains an important challenge within the biopharmaceutical industry.

To date, microfluidic devices have been constructed to study either single-cell or population responses to a variety of factors such as exposure to agonists, electrical stimulation, or variations in the solution composition that may be quiescent or flowing. In general, hydrodynamic forces (or shear stresses) are more significant within microfluidic systems, ${ }^{2}$ compared to open quiescent microtiter plates. Several studies have already shown that

* To whom correspondence should be addressed. Phone: +44(0)141-330 4931. Fax: +44(0)141-330-6002. E-mail: jmcooper@elec.gla.ac.uk.

$\dagger$ University of Glasgow, Glasgow.

* University of Hull, Hull.

$\$$ GlaxoSmithKline Pharmaceuticals.

(1) El-Ali, J.; Sorger, P. K.; Jensen, K. F. Nature 2006, 442, 403-442.

(2) Walker, G.; Zeringueb, H. C.; Beebe, D. J. Lab Chip 2004, 4, 91-97. shear stress can have a range of effects dependent on both the cell type and the local hydrodynamic environment. ${ }^{3-7}$ For example, the severity of shear stress can influence the metabolism of hepatocytes $^{3}$ and the morphology and metabolism of shearsensitive endothelia cells. ${ }^{6,7}$ Outside of the microfluidic environment shear stress has also been found to modulate ion channel (i.e., $\mathrm{K}^{+}, \mathrm{Ca}^{2+}$ ) activation in mechanosensitive cell types, such as endothelial cells ${ }^{8}$ and bone cells. ${ }^{9}$ Furthermore, it has been observed that $\mathrm{Ca}^{2+}$ flux is modulated in artificially constructed bilayers by changes in shear stress..$^{10}$ This latter observation suggests that similar variations in $\mathrm{Ca}^{2+}$ flux may exist even for cell types that are generally regarded as non-mechano-sensitive, when they are subjected to the fluid flow regimes found in microfluidic devices where moderate to high shear stresses can readily exist.

The importance of having an understanding of the fundamental reasons behind variations in cellular-based $\mathrm{Ca}^{2+}$ flux can be appreciated since $\mathrm{Ca}^{2+}$ is generally regarded as a universal intracellular messenger, regulating a diverse range of processes, such as gene transcription, muscle contraction, and cell proliferation, ${ }^{11}$ with localized changes reported in a variety of diseases. ${ }^{12}$ As a consequence, $\mathrm{Ca}^{2+}$ measurement is now one of the most important validation assays in high-throughput drug screening in the pharmaceutical industry. ${ }^{13}$ To date, however, there has only been limited published work on the measurement of intracellular $\mathrm{Ca}^{2+}$ in microfluidic or lab-on-a-chip systems, with examples of

(3) Tanaka, Y.; Yamato, M.; Okano, T.; Kitamori, T.; Sato, K. Meas. Sci. Technol. 2006, 17, 3167-3170.

(4) Jacobs, C. R.; Yellowley, C. E.; Davis, B. R.; Zhou, Z.; Cimbala, J. M.; Donahue, H. J. J. Biomech. 1998, 31, 969-976.

(5) Keane, J. T.; Ryan, D.; Gray, P. Biotechnol. Bioeng. 2003, 81, 211-220.

(6) Gray, B. L.; Lieu, D. K.; Collins, S. D.; Smith, R. L.; Barakat, A. I. Biomed. Microdevices 2002, 4, 9-16.

(7) Nollert, M. U.; Diamond, S. L.; Mcintire, L. V. Biotechnol. Bioeng. 1991, $38,588-602$.

(8) Li, Y.; Haga, H.; Chien, S. J. Biomech. 2005, 38, 1949-1971.

(9) Klein-Nulend, J.; Bacabac, R. G.; Mullender, M. G. Pathol. Biol. 2005, 53, $576-580$.

(10) Chakravarthy, S. R.; Giorgio, T. D. Biochim. Biophys. Acta Biomembranes 1992, 1112, 197-204.

(11) Bootman, M. D.; Collins, T. J.; Peppiatt, C. M.; Prothero, L. S.; MacKenzie, L.; De Smet, P.; Travers, M.; Tovey, S. C.; Seo, J. T.; Berridge, M. J.; Ciccolini, F.; Lipp, P. Cell Dev. Biol. 2001, 12, 3-10.

(12) Rizzuto, R.; Pozzan, T. Nat. Genet. 2003, 34, 135-141.

(13) Monteith, G. R.; Bird, G. St. J. Trends Pharmacol. Sci. 2005, 26, 218-223. 
such work focusing on excitable chondrocyte cells ${ }^{14,15}$ and the myocyte cells. ${ }^{16-18}$ Fundamental studies to evaluate on-chip intracellular $\mathrm{Ca}^{2+}$ analysis as a reliable method for general biophysical and pharmacological screening applications are less well represented in the literature, especially when a non-mechanosensitive cell type is used.

In order to ascertain whether $\mathrm{Ca}^{2+}$ fluxes are induced when non-mechano-sensitive cells are subjected to different shear stresses in a microfluidic environment, we conducted a quantitative evaluation of variations in $\mathrm{Ca}^{2+}$ flux within Chinese hamster ovary (CHO) cells (generally regarded as a non-mechano-sensitive cell) immobilized from a loaded cell suspension. Here, immobilized cells differ from adherent cells in that the latter are cultured and then spread over a substrate. One pragmatic reason for immobilizing the cell within the channel is that the process fixes its position, thereby helping with signal tracking (intracellular $\mathrm{Ca}^{2+}$ levels will change in both space and amplitude over fast time scales ${ }^{11}$ ).

This $\mathrm{Ca}^{2+}$ flux was measured using the $\mathrm{Ca}^{2+}$ sensitive fluorescence indicator, and experiments were performed within a platform comprising a microfluidic manifold clamped to a preprepared substrate. This allowed the manifold to be sterilized and substrates chemically modified prior to integration. The particular silane and collagen surface modifications described below were found to provide an effective means to both immobilize cells onchip and maintain their viability.

\section{MATERIALS AND METHODS}

Cell Culture. All cell culture media and serum were supplied by Invitrogen Corporation. The $\mathrm{CHO}$ cell line was supplied from GSK. CHO cells were cultured in $25 \mathrm{~cm}^{2}$ tissue culture flasks at $37^{\circ} \mathrm{C}$ in a humidified atmosphere with $5 \% \mathrm{CO}_{2} / 95 \%$ air. The cells were incubated in DMEM/F12 medium supplemented with $10 \%$ fetal calf serum and $4 \mathrm{mM}$ L-glutamine. All chemicals were supplied by Sigma Limited (Poole, U.K.), unless otherwise indicated.

Cells were grown to near confluence in the culture flasks and then suspended with $0.05 \%$ trypsin-EDTA solution. The concentration of suspended cells was determined using a hemeocytometer, before being introduced into the microfluidic chip. The viability of cells was determined using the $0.4 \%$ trypan blue solution. An average measurement of the percent viable cells in four randomly selected fields of view was used as a measure of cell viability.

Cell Loading and Immobilization. Cells in suspension at a concentration of about $2.5 \times 10^{6}$ cells $/ \mathrm{mL}$ were pumped into a microfluidic channel at a flow rate of $1 \mu \mathrm{L} / \mathrm{min}$. Once in the channel, they were left undisturbed for $30 \mathrm{~min}$ to allow attachment to the channel surface. Subsequently, unattached cells were washed away at a flow rate of $1 \mu \mathrm{L} / \mathrm{min}$. Adhesion experiments were performed to investigate the density of attached cells over a range of shear stresses, starting at low flow rates and then increasing. During a given measurement, a continuous flow was

(14) Chao, P. H. G.; West, A. C.; Hung, C. T. Am. J. Physiol.: Cell Physiol. 2006, 291, C718-C725.

(15) Donahue, S. W.; Donahue, H. J.; Jacobs, C. R. J. Biomech. 2003, 36, 3543.

(16) Klauke, N.; Smith, G. L.; Cooper, J. M. Biophys. J. 2006, 91, 2543-2551.

(17) Li, X.; Li, P. C. H. Anal. Chem. 2005, 77, 4315-4322.

(18) Werdich, A. A.; Lima, E. A.; Ivanov, B.; Ges, I.; Anderson, M. E.; Wikswo, J. P.; Baudenbacher, F. J. Lab Chip 2004, 4, 357-362.

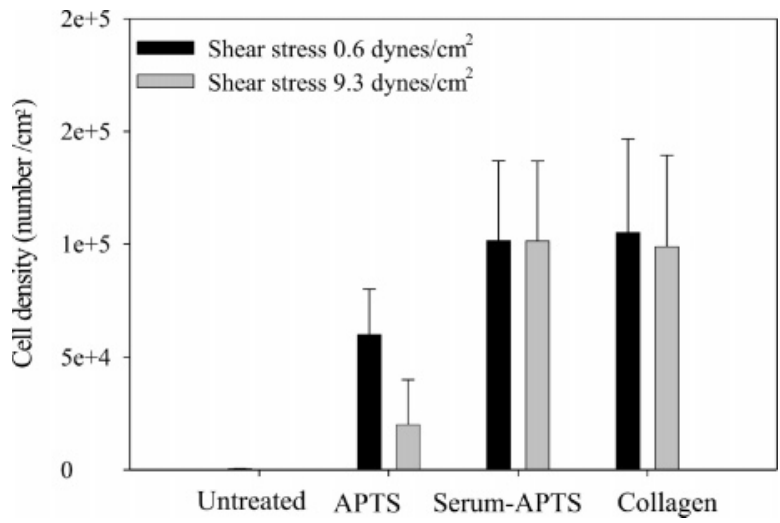

Figure 1. Comparison of immobilized cell densities on differently modified microfluidic channels at both low (black) and elevated shear stresses (gray). Statistical results of three independent experiments for each condition. The seeding density was $2.5 \times 10^{6} \mathrm{cells} / \mathrm{mL}$.

maintained for 2 min, during which time the chip was imaged in situ. This was followed by a 1 min quiescent period, before retesting the cells at a higher flow rate (inducing progressively higher shear stresses). In all cases, the maximum Reynolds number was less than 0.1 , indicating that flow was laminar in nature.

Images were taken at the center of the channels, away from the side walls, to ensure the full development of the flow profile. Cell number and morphology in the field of view were recorded in real time using bright-field phase contrast microscopy. Cell densities attached on the surfaces were determined by dividing the number of cells left in the field of view after each step by the surface area of the field of view.

Intracellular $\mathbf{C a}^{2+}$ Flux. In order to quantitatively evaluate the intracellular $\mathrm{Ca}^{2+}$ level, a well-established fluorescence intensity measurement using Fluo-4 $\mathrm{AM} \mathrm{Ca} \mathrm{Ca}^{2+}$ indicator dye was employed in this study. ${ }^{19}$ This involved labeling cells with the dye and subsequently monitoring any change in fluorescence intensity as the cells responded to shear stress.

Cell Labeling. The $\mathrm{Ca}^{2+}$ fluorescent dye solution comprised 2 $\mu \mathrm{M}$ Fluo-4 AM (Invitrogen Molecular Probes) in a Tyrode buffer. The Tyrode buffer was prepared from a stock containing $145 \mathrm{mM}$ $\mathrm{NaCl}, 2.5 \mathrm{mM} \mathrm{KCl}, 10 \mathrm{mM}$ HEPES, $10 \mathrm{mM}$ D-glucose, $1.2 \mathrm{mM}$ $\mathrm{MgCl}_{2}, \mathrm{pH}$ 7.4. Final concentrations of $2.5 \mathrm{mM}$ probenecid and $1.5 \mathrm{mM} \mathrm{CaCl}_{2}$ were added shortly before the buffer was used. Suspended cells were centrifuged and washed with the Tyrode buffer at $100 \mathrm{~g}$ for $5 \mathrm{~min}$ to remove the medium. They were resuspended in the labeling buffer to a concentration of $\sim 2.5 \times$ $10^{6} / \mathrm{mL}$ and incubated at $37^{\circ} \mathrm{C}$ for $10 \mathrm{~min}$.

Signal Recording. Fluorescence imaging was used to record the change of intracellular $\mathrm{Ca}^{2+}$ level using the Fluo-4 AM labeled cells. The labeled suspended CHO cells were loaded into microfluidic channels and left undisturbed in darkness for $30 \mathrm{~min}$ to allow further incorporation of the dye into cells and for cell attachment to the substrate surface to occur. It was found that such a labeling procedure provided a strong fluorescence signal from within cells. Importantly, the cell-permeable Fluo-4 AM ester fluoresces only after it enters the cells, giving low background signals. ${ }^{19}$ After this 30 min incubation, Tyrode buffer was then

(19) Takahashi, A.; Camacho, P.; Lechleiter, J. D.; Herman, B. Physiol. Rev. 1999 $79,1089-1125$. 

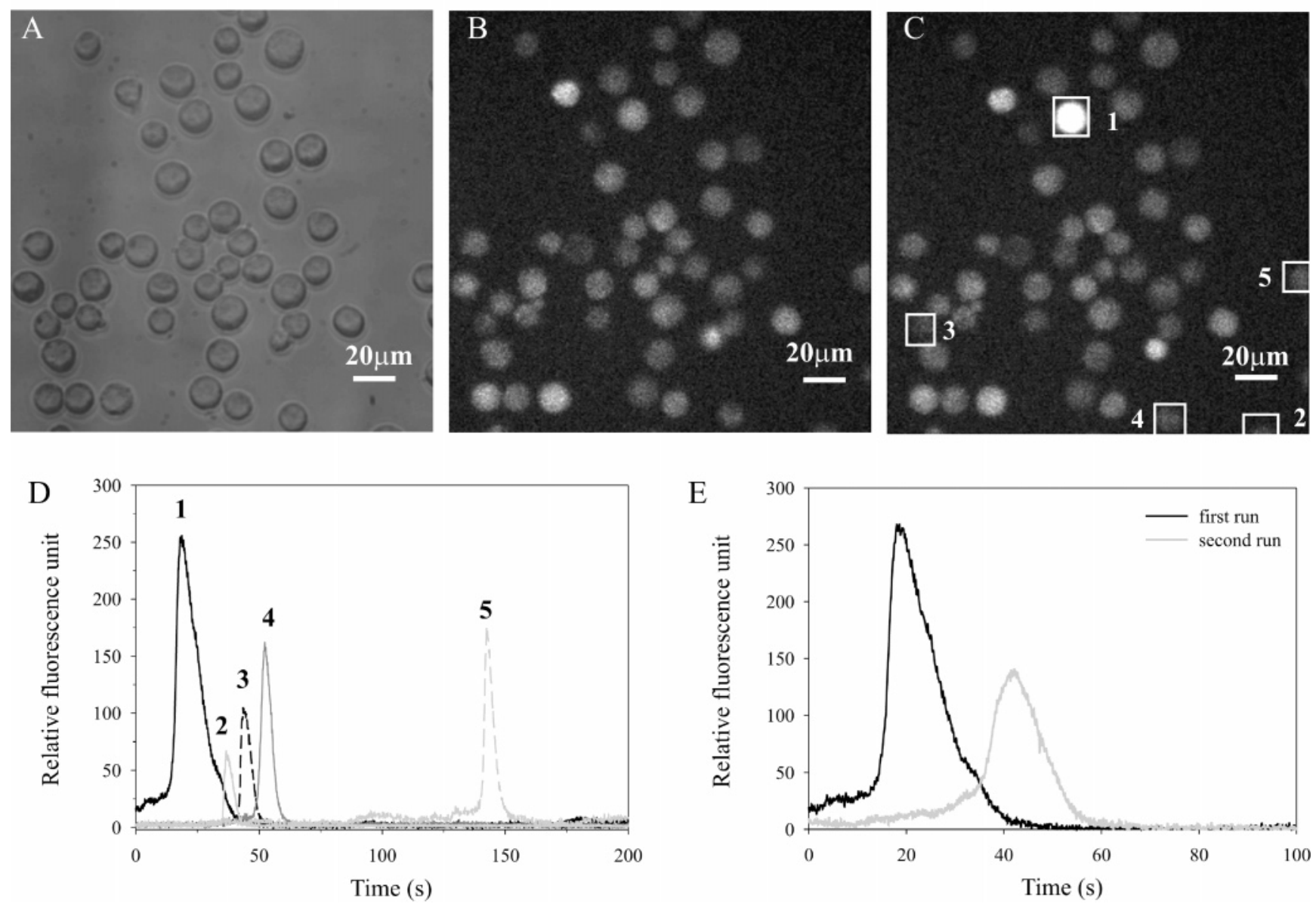

Figure 2. Shear-stress-induced intracellular $\mathrm{Ca}^{2+}$ transient measured from spherical suspended cells. Transmitted light image (A) and fluorescent images ( $\mathrm{B}$ and $\mathrm{C}$ ) of cells in the center of the $500 \mu \mathrm{m}$ wide microfluidic channel. The fluorescent image (B) represents background in the absence of any flow, while the fluorescent image (C) shows one cell (cell 1) responding to shear stress at $9.3 \mathrm{dynes} / \mathrm{cm}^{2} 16 \mathrm{~s}$ after the onset of flow. During the $2 \mathrm{~min}$ of recording, five cells respond to the shear stress (each is surrounded by a square, and the sequence is shown in the Supporting Information). The $\mathrm{Ca}^{2+}$-sensitive fluorescent dye Fluo-4 was used to indicate intracellular $\mathrm{Ca}^{2+}$ flux. (D) Corresponding relative fluorescence unit profile of the responding cells in $(C)$, showing the temporal (transient) nature and magnitude of the response. For the purpose of comparison, the relative fluorescence unit was plotted after subtraction of the particular quiescent baseline fluorescence unit to an individual cell. Panel $E$ shows a representative example of the recovery of the response of cells after shear stress was resumed in the second run. A representative profile of cell 1 in (C) is shown.

flowed across the attached cells at successively higher rates, which gave an increase in shear stress. At each flow rate, continuous flow was maintained for 6 min during which time three different intracellular regions were recorded for 2 min each. After each recording, the cells were maintained in quiescent buffer for $1 \mathrm{~min}$, before performing the next measurement at a higher flow rate.

Data Acquisition and Analysis. Both transmission and fluorescent images were recorded using a Zeiss Axiovert inverted fluorescence microscope coupled to a monochrome cooled CCD digital camera (Andor iXon, Andor Technology). A filter set, containing an exciter D475/40, an emitter E510, and a beam splitter Dichroic 495, was used for the fluorescence imaging. The intensity of the excitation light was adjusted using neutral density filters $(O D=1)$ to minimize photobleaching of the dye. Realtime fluorescence recordings were made for $3 \mathrm{~min}$ at a rate of 10 frames per second with a nominal gain of 200. Confocal images were recorded using a Zeiss LSM 510 Meta confocal system with $488 \mathrm{~nm}$ argon ion laser using a $\times 63$ oil immersion lens. $Z$-stacks were recorded to measure cell size in three dimensions.

The fluorescence intensity of whole discrete individual cells was obtained using the Andor iQ1.4 image software. The maxi- mum responding amplitude (simplified as response) was calculated accordingly: The cell's response was expressed as $\left(F_{\text {peak }}-\right.$ $\left.F_{0}\right) / F_{0} \times 100 \%$, where $F_{\text {peak }}$ is the peak fluorescence intensity and $F_{0}$ the baseline. ${ }^{19}$ For all the measurements, fluorescence intensity was background subtracted using the fluorescence intensity of an adjacent cell-free region. The baseline fluorescence intensity $\left(F_{0}\right)$ was taken as an average initial value over $10 \mathrm{~s}$ before applying either shear stress or UTP solutions.

\section{RESULTS AND DISCUSSION}

The overall aim of this work was to assess the potential use of microfluidics as a reliable method for high-throughput cellular functional assay. In order to provide a suitable platform for such a study, it was necessary to design a device capable of accurately and reliably testing cell responses under different flows and different chemical stimuli. The particular requirements of this study, included the generation of statistically meaningful information, the creation of uniform, well-controlled flow profiles around cell, and the production of a disposable device (or disposable cellcontact part) to reduce the potential for contamination. The resulting microfluidic platform (Supporting Information Figure S1) 
was then used to assess the effect of commonly used hydrodynamic conditions on quantitative intracellular $\mathrm{Ca}^{2+}$ cellular assay.

Microfluidic Device Design and Fabrication. The microfluidic device developed for this study is shown in Supporting Information Figure S1, parts A and B. The substrate was modified using a biocompatible adhesion matrix to increase the likelihood of cell attachment and enhance viability. The sealing mechanism maintained the integrity of this adhesion matrix layer in the microchannel. Leakage from the chip was tested using a colored dye, and it was found that the device formed in this way remained robust even with shear stresses of 120 dynes $/ \mathrm{cm}^{2}$ (Supporting Information video 1). Note: none of the experiments using cells as discussed below involved shear stresses that exceeded 10 dynes $/ \mathrm{cm}^{2}$, as calculated from eq 1 .

Many reported microfluidic devices for cellular assays have channels $10-100 \mathrm{~mm}$ wide and less than $50 \mathrm{~mm}$ high, ${ }^{20}$ leading to shear stresses in the range of many tens of dynes $/ \mathrm{cm}^{2}$ even with low flow rates of $2 \mu \mathrm{L} / \mathrm{min}$. The actual shear stress on such cells may, in fact, be even higher due to a high cell radius/channel height ratio. ${ }^{21}$ In general, rapid on-chip cellular measurement requires a sufficiently fast flow rate for cell or reagent delivery. To take into account both the speed of the reagent delivery and the resultant shear stress, hydrodynamic conditions that lead to low shear stresses of less than 10 dynes $/ \mathrm{cm}^{2}$ were assessed in this study.

To estimate hydrodynamic mechanical loading on the cells, the effects of cell topology and microchannel design were also taken into account. Gaver and Kute have previously demonstrated that the actual mechanical stress on an attached round-shaped cell was significantly greater than that experienced in a cell-free system when the ratio of cell size to channel height $(R / H)$ was over $0.25 .^{21} \mathrm{Lu}$ et al. found that when $R / H=0.16$, the average shear stress on a nonflat cell was comparable to that of an empty channel. ${ }^{22}$

In this study, after cell attachment for $30 \mathrm{~min}$, the mean diameter of $\mathrm{CHO}$ cells (from base membrane to cell top) was $\sim 10.5 \mu \mathrm{m}$, as determined by confocal microscopy. The channel height of the chips chosen for this study was $140 \mu \mathrm{m}(R / H<$ 0.1 ), so avoiding any amplification of mechanical stress (as predicted by others ${ }^{21,22}$ ). In other words, when $R / H$ is very small, the shear stress on the cell is equivalent to the wall shear stress.

The wall shear stress, which takes into account both flow rate and the geometry of chips, was used in the study as the nominal mechanical loading on cells, according to eq $1:^{22}$

$$
\tau=-\frac{12 v v}{h}
$$

where $\tau$ is shear stress (dynes $\left./ \mathrm{cm}^{2}\right), v$ is liquid viscosity $(\mathrm{g} / \mathrm{cm}$. $\mathrm{s}), v$ is linear velocity $(\mathrm{cm} / \mathrm{s})$, and $\mathrm{h}$ is the flow channel height. As illustrated in eq 1, increases in flow rate lead to a proportional increase in shear stress for fixed geometry systems.

Surface Modification for Cell Immobilization. When using unmodified glass substrates to construct the base of microfluidic

(20) Andersson, H.; van den Berg, A. Sens. Actuators, B 2003, 92, 315-325.

(21) Gaver, D. P.; Kute, S. M. Biophys. J. 1998, 75, 721-733.

(22) Lu, H.; Koo, L. Y.; Wang, W. M.; Lauffenburger, D. A.; Griffith, L. G.; Jensen, K. F. Anal. Chem. 2004, 76, 5257-5264.
A

Flow rate $(\mu \mathrm{l} / \mathrm{min})$

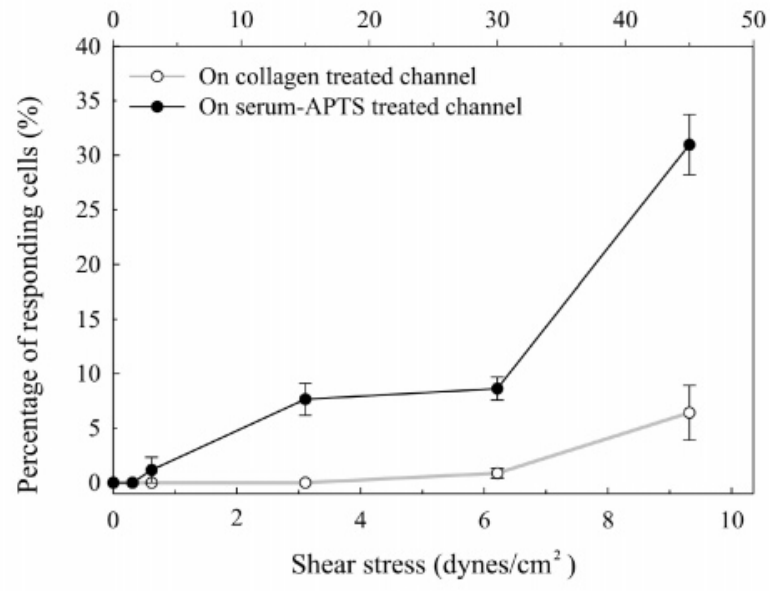

B

Flow rate $(\mu \mathrm{l} / \mathrm{min})$

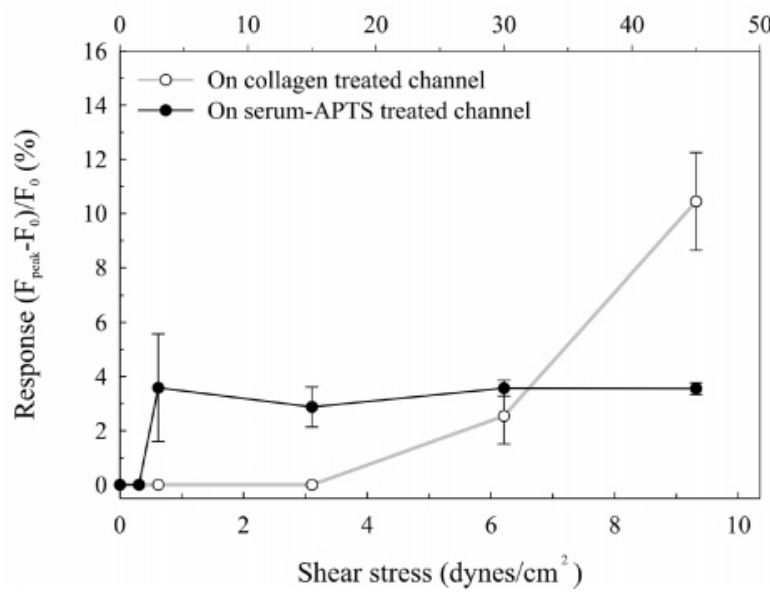

Figure 3. Shear-induced $\mathrm{Ca}^{2+}$ flux as a function of shear stress. (A) Figure shows the dependence of responding population to the shear stress; panel B shows the amplitude as a function of shear stress. The flow rates and the corresponding shear stresses were shown on the top and the bottom of the $x$-axis, respectively. The error bar is the standard error $(n=270)$.

channels, it was found that few cells attached, even at a low flow rate of $1 \mu \mathrm{L} / \mathrm{min}$ and high loading density of $1 \times 10^{7}$ cells $/ \mathrm{mL}$. Modification with collagen and APTS silane was used to enhance cell attachment. The surface modification process was optimized off-chip (Supporting Information). Initial attachment of $\mathrm{CHO}$ cells on the modified surfaces was examined by plating the substrates for $30 \mathrm{~min}$ with serum-free $\mathrm{CHO}$ suspended cells at a seeding density of $2.5 \times 10^{6}$ cells $/ \mathrm{mL}$, followed by rinsing with serumfree culture medium. Attachment densities were higher on the collagen-treated surface compared to untreated glass. It was observed that such an enhancement was significantly higher on a surface treated with collagen at concentrations $>0.4 \mathrm{mg} / \mathrm{mL}$, Supporting Information Figure S2A, although there was no significant further enhancement at higher concentrations. Overnight incubation of the attached cells with serum-free culture medium also showed an enhancement in cell growth after the collagen treatment (Supporting Information Figure S2B), suggesting the role of an improved biocompatible extracellular matrix. An off-chip-modified substrate was used to construct the device, since this provided a flexible way of integrating different surface 
A

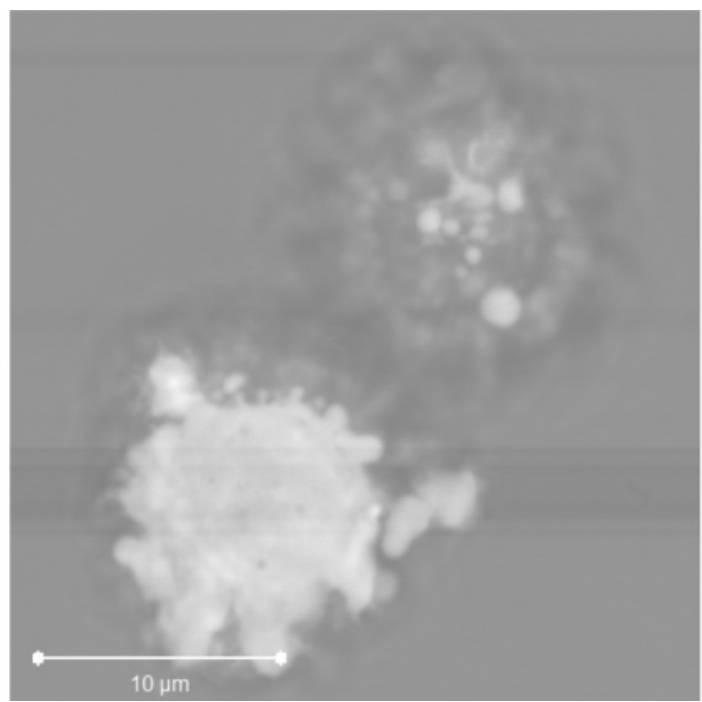

B
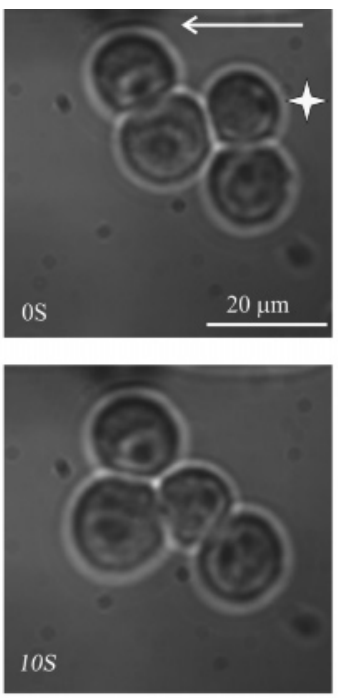
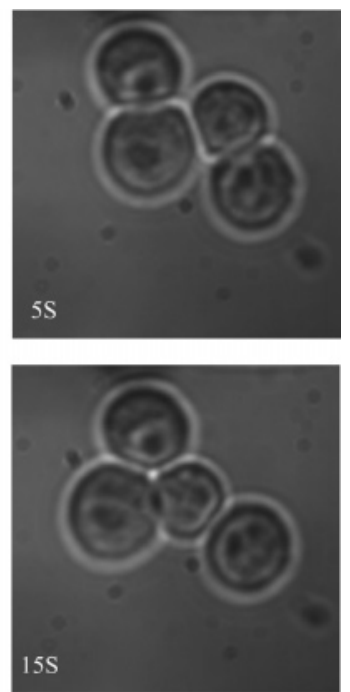

Figure 4. (A) Fluorescence confocal images show the different degree of attachment of two cells, 15 min after loading onto the substrates. Cells were washed and loaded with $2 \mu \mathrm{M}$ calcein AM for fluorescence imaging. The images were taken on the plane near the substrate. The contact area that cells forms with the substrate is indicated by the fluorescence intensity. The large difference in the contact area of two cells indicates an inherent heterogeneity in cell attachment. The heterogeneity persists for at least $2 \mathrm{~h}$. (B) Time series of bright-field images showing cell movement due to high shear stress $\left(9.3\right.$ dynes $\left./ \mathrm{cm}^{2}\right)$. The white star indicates the moving cell. In both $(A)$ and $(B)$, surfaces had been treated with serum-APTS silane. The white arrow indicates flow direction.

functionalizations with microfluidics. No leakage was found over the range of shear stresses investigated.

The densities of attached cells in the resultant microchannels under various hydrodynamic conditions were investigated, and the results are shown in Figure 1. After initial loading of cells at a low shear stress of $\sim 0.6 \mathrm{dyn} / \mathrm{cm}^{2}$, cell attachment densities increased by 2 orders of magnitude on an APTS silane treated substrate, and by an additional factor of 2 on a collagen-treated substrate, in comparison to that obtained on an unmodified glass substrate. More than half of the cells attached on the APTS silane treated surface were lost at a shear stress of $\sim 9.3$ dynes $/ \mathrm{cm}^{2}$, whereas most $(>95 \%)$ cells on the collagen-treated surface remained. However, both cell attachment density and adhesion strength were enhanced if the APTS silane treated surface was first primed with a serum containing culture medium. This latter modification achieved a similar performance to that of a collagentreated surface and is possibly due to the adsorption of soluble proteins, such as fibronectin (or other attachment factors) onto the positively charged APTS silane modified glass surface. ${ }^{23}$ Both collagen and serum-APTS silane treatment of microchannels promoted rapid cell attachment and enhanced immobilization density, allowing statistical studies to be made.

Intracellular $\mathrm{Ca}^{2+}$ Flux Induced by Shear Stress. Reliable functional information can only be obtained from viable cells. The viability of cells on the collagen-modified surface under the highest shear stress of $\sim 9.3$ dynes $/ \mathrm{cm}^{2}$ was found to be over $96 \%$, which was virtually identical to that determined before loading (96.7 \pm $0.6 \%$ ). We found that even a brief exposure to low levels of shear stress induced an intracellular $\mathrm{Ca}^{2+}$ flux in the $\mathrm{CHO}$ cells, although no gross morphological changes were observed. A representative series of fluorescence images of shear-induced $\mathrm{Ca}^{2+}$ flux of $\mathrm{CHO}$ cells at 9.3 dynes $/ \mathrm{cm}^{2}$ are shown in Figure 2, parts Band C. After the onset of the flow, a fraction of the cells start to respond,

(23) Steele, J. G.; Dalton, B.; Johnson, G.; Underwood, P. Biomaterials 1995, 16, 1057-1067. resulting in transients $(\sim 20 \mathrm{~s})$ of high levels of intracellular $\mathrm{Ca}^{2+}$ concentration, as indicated in the fluorescence intensity profile (Figure 2D). The $\mathrm{Ca}^{2+}$ flux within each of the cells was different with respect to its point of initiation, its amplitude, and the frequency of oscillation of its response (details shown in Supporting Information video_2). No cell responded when the fluid flow was stopped. In some cases, cells were found to respond to stimulation when the same, or an increased, shear stress was resumed, although the amplitude of the response was always reduced, Figure 2E.

Characteristics of Shear-Induced Intracellular $\mathrm{Ca}^{2+}$ Flux. To understand the nature of shear-induced intracellular $\mathrm{Ca}^{2+}$ flux and the relationship of cell response to shear stress, further statistical studies were carried out over a range of shear stress from 0.01 to $9.3 \mathrm{dynes} / \mathrm{cm}^{2}$. The use of either serum-APTS silane modified or collagen-modified substrates for the construction of chips gave rise to a high density of attached suspended cells $(\sim 40$ to $\sim 50$ cells in a field of view of $200 \times 200 \mu \mathrm{m}^{2}$ ).

Six different regions comprising over 270 cells were recorded to permit a statistically meaningful evaluation which showed that there was a threshold for shear-induced intracellular $\mathrm{Ca}^{2+}$ transition of $\mathrm{CHO}$ cells whether attached on serum-APTS silane treated surfaces $\left(>0.31\right.$ dynes $\left./ \mathrm{cm}^{2}\right)$ or on collagen-treated surfaces $(>3.1$ dynes $\left./ \mathrm{cm}^{2}\right)$, as shown in Figure 3A. In both cases there was a clear trend showing that the percentage of the cell population that was responding increased with increased shear stress, although the amplitude of the responses varied. This latter variation was constant over the range of shear stress studied, once the $\mathrm{Ca}^{2+}$ response was triggered. In addition, cells attached on a serumAPTS silane treated surface had a higher percentage of responding population than those on the collagen-treated surface, even though cell densities attached on both surface types were similar (Figure 3B). 
The intracellular $\mathrm{Ca}^{2+}$ transition can be activated through a variety of mechanisms, such as ligand-gated ion channels or via membrane depolarisation. ${ }^{11}$ In this series of experiments, there were no chemical stimuli present, and the observed shear-induced intracellular $\mathrm{Ca}^{2+}$ flux in a nonexcitable $\mathrm{CHO}$ cell may therefore be directly related to mechanically triggered channel opening ${ }^{11}$ due to membrane depolarization. Using confocal microscopy, we found that the extent of cell attachment (measured as the "in contact" surface area) on the same chip showed a degree of variability, ranging from $\sim 10$ to $110 \mu \mathrm{m}^{2}$. A $z$-slice taken at the level of the substrate revealed the area of attachment, and a representative example is shown in Figure 4A. At low levels of shear stress, on both collagen and serum-ATPS treated surfaces, no sign of cell movement or distortion was observed in any cells in the field of view. At higher levels of shear stress (i.e., 9.3 dynes/ $\mathrm{cm}^{2}$ ) those less firmly attached cells were moved in the direction of flow and cell membranes showed visible deformation (as shown in Figure 4B). This may explain the increased population of responding cells with increasing shear stress, although deformation did not necessary lead to intracellular $\mathrm{Ca}^{2+}$ release, as shown in Figure 2 and the Supporting Information video_2.

The observed quantitative difference in shear-induced intracellular $\mathrm{Ca}^{2+}$ flux for cells attached on serum-APTS silane treated and collagen-treated microchannels also suggested a possible influence of focal adhesion strength, as illustrated in a number of other studies. ${ }^{24,25}$ Undoubtedly, the biophysical mechanisms responsible for these observations are complex and will form the basis of future studies. However, the phenomenon clearly demonstrates the high probability of hydrodynamic influence on cellular functionality, even for cells that are generally regarded as being nonmechanically sensitive, such as $\mathrm{CHO}$ cells.

Implications of Shear-Induced Intracellular $\mathbf{C a}^{2+}$ Flux. It is well-known that the presence of chemical stimuli, such as uridine 5 -triphosphate tris salt (UTP), can induce intracellular $\mathrm{Ca}^{2+}$ flux. Figure 5 shows a typical intracellular $\mathrm{Ca}^{2+}$ flux in response to $1 \mu \mathrm{M}$ UTP (black trace), and the shear-induced response in the absence of UTP (gray trace). Clearly, these two responses are similar, suggesting that the shear stress mimics the responses that can be induced by UTP. The possibility therefore exists that shear-induced intracellular $\mathrm{Ca}^{2+}$ flux could bias information in microfluidic assays involving the functional screening of chemical stimuli (for example, agonists generally used for activation of ligand-gated ion channels). Careful on-chip evaluation is therefore essential, in order to ensure that cells are being assessed under conditions that reveal a genuine response to the analytes of interests.

(24) Allen, L. T.; Tosetto, M.; Miller, I. S.; O'Connor, D. P.; Penney, S. C.; Lynch, I.; Keenan, A. K.; Pennington, S. R.; Dawson, K. A.; Gallagher, W. M. Biomaterials 2006, 27, 3096-3108.

(25) Keselowsky, B. G.; Collard, D. M.; Garcia, A. J. J. Biomed. Mater. Res. 2003, $66 A, 247-259$

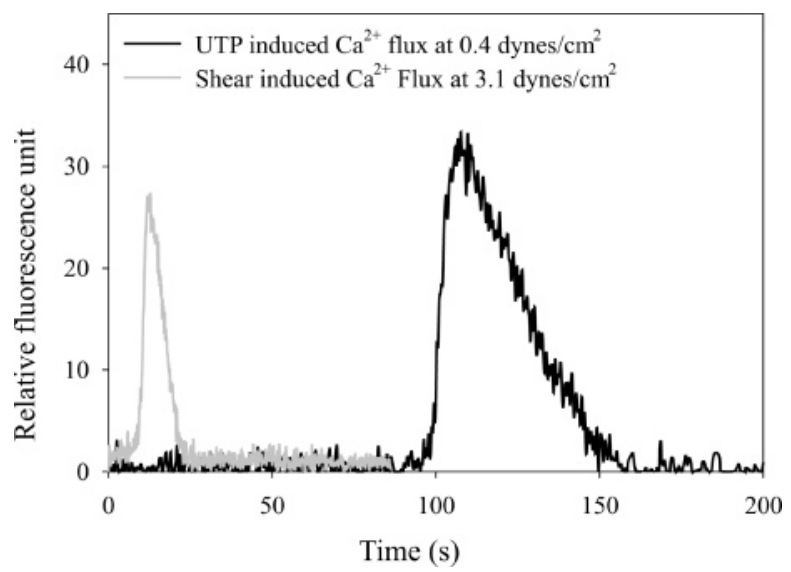

Figure 5. Comparison of shear-induced $\mathrm{Ca}^{2+}$ flux at a shear stress of 3.1 dynes $/ \mathrm{cm}^{2}$ with agonist UTP $(1 \mu \mathrm{M})$ induced $\mathrm{Ca}^{2+}$ flux. The UTP solution was delivered at $2 \mu \mathrm{L} / \mathrm{min}$ (shear stress at 0.4 dynes/ $\mathrm{cm}^{2}$ ), which was below the threshold of shear stress inducing intracellular $\mathrm{Ca}^{2+}$ flux. At this shear stress, no $\mathrm{Ca}^{2+}$ flux was observed in the absence of UTP. Both peaks present similar transient responses and amplitude, which could lead to biased interpretation (i.e., shearinduced $\mathrm{Ca}^{2+}$ flux could be mistaken for a UTP-induced effect).

\section{CONCLUSIONS}

A systematic evaluation of a quantitative functional assay using immobilized spherical nonmechanically sensitive $\mathrm{CHO}$ cells in a microfluidic system was investigated. The device enabled a high density of immobilized, viable cells to be analyzed on-chip. By using intracellular $\mathrm{Ca}^{2+}$ analysis of $\mathrm{CHO}$ cells as a model system, we found that the microenvironment of the microfluidic device, particularly that of shear stress, could exert a significant influence on cell functionality. The possibility of this effect leading to biased information on functional cellular analysis exists. Careful on-chip assessment is therefore vital in future applications of microfluidics and lab-on-a-chip in biomedical and pharmaceutical fields. Further quantification of cell response to agonists (i.e., UTP) on-chip in comparison with traditional pharmaceutical method is ongoing.

\section{ACKNOWLEDGMENT}

The DTI is acknowledged for funding this research. We also acknowledge Epigem Ltd. for fabrication of the sealing block. We also thank Drs. Andrew Glidle, Paul Monaghan, and Helen Sedgwick for helpful discussions.

\section{SUPPORTING INFORMATION AVAILABLE}

Detailed information on microfluidics fabrication and surface modification; one video clip of the leakage test on the formed device and one video clip of the shear-induced $\mathrm{Ca}^{2+}$ flux at shear stress of 9.3 dynes $/ \mathrm{cm}^{2}$. This material is available free of charge via the Internet at http://pubs.acs.org.

Received for review May 31, 2007. Accepted June 7, 2007. AC071146K 